\title{
SIGNIFICANCE OF DNA BASE COMPOSITION IN THE CLASSIFICATION OF YEAST GENERA HANSENIASPORA AND KLOECKERA
}

\author{
TAKASHI NAKASE AND KAZUO KOMAGATA ${ }^{1}$ \\ Central Research Laboratories, Ajinomoto Co., Inc., Kawasaki, Japan
}

(Received January 19, 1970)

\begin{abstract}
The base composition of DNA (GC content) of 31 cultures of Hanseniaspora and its imperfect counterpart Kloeckera, which represented 14 species, was studied. The GC content of these apiculate yeasts ranged from 26.8 to $38.0 \%$. Thirty-one cultures employed were divided into 4 groups on the basis of their GC contents, and this grouping agreed with that based on biochemical criteria commonly employed in yeast taxonomy. The first group (H. osmophila-K. africana) exhibited the GC content of $37.3-38.0 \%$, and assimilated maltose but not glycerol or calcium-2-ketogluconate. The second group (K. javanica) exhibited the GC content of $33.7-34.6 \%$ and assimilated glycerol but not maltose or calcium-2-ketogluconate. The third group (H. guilliermondii, $H$. uvarum-K. apiculata) exhibited the GC content of $31.0-31.7 \%$ and assimilated calcium-2-ketogluconate but not maltose or glycerol. The last group ( $H$. valbyensis-K. japonica) exhibited the GC content of 26.8-27.6\%, and did not assimilate maltose, glycerol, and calcium-2-ketogluconate. Relationship between the species of Hanseniaspora and its counterpart species of Kloeckera was discussed.
\end{abstract}

The genus Hanseniaspora and its imperfect counterpart Kloeckera are the most frequently encountered genera of apiculate yeasts in various natural products. Since the first description of an apiculate yeast, Saccharomyces apiculatus (1), a number of papers dealing with these common apiculate yeasts have been published. LODDER and KREGER-VAN RIJ (2) recognized only one species of Hanseniaspora and 8 species of Kloeckera in their monograph on yeasts. Thereafter, several new species and new combinations were described (3-5). MILLER and PHAFF (6) made an extensive study of apiculate yeasts including several new species mentioned above. They reported that the genus Hanseniaspora and its imperfect form Kloeckera make a natural group, and found that these yeasts comprised 4 groups. They recognized 3 species, H. osmophila, H. uvarum, and H. valbyensis, in Hansenia-

1 Present Address: Institute of Applied Microbiology, University of Tokyo, Hongo, Tokyo. 
spora and 4 species and a variety, $K$. africana, $K$. apiculata, $K$. corticis, $K$. javanica, and K. javanica var. lafarii, in Kloeckera. H. vineae was regarded as a synonym of $H$. osmophila by these workers, while NovíK and ZsOLT (7) considered that $H$. vineae should be represented as a new genus Vanderwaltia, because it formed ascospores with warty wall. On the other hand, TSUCHIYA et al. (8) recognized 3 groups in Hanseniaspora-Kloeckera on the basis of antigenic structure. Further, they deduced from the standpoint of antigenicity that $K$. javanica might be a hybrid species of $K$. apiculata and $K$. africana. This deduction was supported by SPENCER and GORIN (9) on the basis of a proton magnetic resonance spectra of mannans isolated from these apiculate yeasts.

The present authors investigated the DNA base composition (GC content) of 31 cultures of Hanseniaspora and Kloeckera, and found that these yeasts were divided into 4 groups by the difference of their GC contents. The present paper deals with the GC content of Hanseniaspora and Kloeckera in relation to an evaluation of systematic studies by several workers, and that of taxonomic criteria commonly employed in yeast taxonomy.

\section{MATERIALS AND METHODS}

Microorganisms. Twelve cultures of Hanseniaspora which represented 5 species, and 19 cultures of Kloeckera which represented 9 species were employed. Sources of cultures are shown in Table 1.

Investigation of carbon assimilation, sugar fermentation, and vitamin requirement. Assimilation of carbon compounds and fermentation of sugars were investigated by the method of WICKERHAM (10) with a relatively heavy inoculum. Requirement of vitamins was determined by the procedure previously reported (11).

Cultivation and harvest of yeasts, and isolation of DNA. Cultivation and harvest of yeasts, and isolation of DNA followed the procedures previously reported (12). Usually $5-10 \mathrm{~g}$ of wet packed cells was employed for isolation of DNA.

Determination of DNA base composition. The DNA base composition was calculated from the thermal denaturation temperature $(\mathrm{Tm})$ of DNA according to the procedure of MARMUR and DOTY (13), using the relation of $\mathrm{Tm}=69.3+0.41$ (GC content). Tm was measured using the apparatus described by YAMADA and KOMAGATA (14), of which a thermosensor calibrated against a reference thermometer authorized by the National Research Laboratory of Metrology of Japan was directly inserted into DNA solutions.

\section{RESULTS}

DNA base composition (GC content) calculated from the $\mathrm{Tm}$ are shown in Table 1. All the DNA preparations obtained from Hanseniaspora and 
Table 1. DNA base composition of the genera Hanseniaspora and Kloeckera.

\begin{tabular}{|c|c|c|c|c|c|c|c|}
\hline Group & Species & Strain & Source & $\begin{array}{l}\mathrm{Tm} \\
\left({ }^{\circ} \mathrm{C}\right)\end{array}$ & $\begin{array}{c}\mathrm{GC} \\
\text { content } \\
(\text { mol. } \%)\end{array}$ & $\begin{array}{c}h \\
\max ^{a}\end{array}$ & $\begin{array}{c}\mathrm{T} \\
\left({ }^{\circ} \mathrm{C}\right)\end{array}$ \\
\hline \multirow{14}{*}{1} & \multirow[t]{2}{*}{ H. osmophila } & $\mathrm{AJ}^{b} 5186$ & \multirow[t]{2}{*}{$\mathrm{J}^{c} 13013\left(\mathrm{CBS}^{d}\right.$ 2568) } & 84.8 & 37.8 & 1.35 & 4.0 \\
\hline & & "I & & 84.6 & 37.3 & 1. 40 & 3.8 \\
\hline & H. vineae & AJ 5182 & J 13009 (CBS 2171) & 84.8 & 37.8 & 1.26 & 3. 7 \\
\hline & $\prime \prime$ & AJ 5183 & J 13010 (CBS 5068) & 84.6 & 37.3 & 1.23 & 3.4 \\
\hline & K. africana & AJ 5172 & K. antillarum J 5030 & 84.9 & 38.0 & 1.25 & 3.9 \\
\hline & \multirow{3}{*}{ /I } & $\prime \prime$ & (CBS 280) & 84.7 & 37.6 & 1.28 & 3.6 \\
\hline & & AJ 5173 & J 5037 (CBS 277) & 84.9 & 38.0 & 1.35 & 4.0 \\
\hline & & $\prime \prime$ & & 84.8 & 37.8 & 1. 20 & 3.5 \\
\hline & "I & AJ 5174 & not recorded & 84.7 & 37.6 & 1.31 & 3.9 \\
\hline & K. corticis & AJ 5171 & J $5028\left(\mathrm{IFO}^{e} 0631\right)$ & 84.8 & 37.8 & 1. 26 & 3.8 \\
\hline & & "I & & 84.6 & 37.3 & 1. 34 & 4.1 \\
\hline & "I & AJ 5178 & J 13005 & 84.8 & 37.8 & 1.34 & 4.4 \\
\hline & & /l & (H. valbyensis IFO 0670) & 84.7 & 37.6 & 1.22 & 3.7 \\
\hline & K. magna & AJ 5198 & J 5042 & 84.7 & 37.6 & 1.27 & 3. 7 \\
\hline \multirow{5}{*}{2} & K. antillarum & AJ 5207 & IFO 0669 & 83.1 & 33.7 & 1.34 & 4.7 \\
\hline & javanica & AJ 5195 & J 5039 & 83.5 & 34.6 & 1.22 & 5.2 \\
\hline & & AJ 5196 & J 5040 & 83.3 & 34.1 & 1.28 & 4.7 \\
\hline & K. jensenii & AJ 5199 & J 5043 & 83.2 & 33.9 & 1.31 & 5.4 \\
\hline & lafarii & AJ 5197 & J 5041 & 83.2 & 33.9 & 1.33 & 5.3 \\
\hline \multirow{11}{*}{3} & H. guilliermondii & AJ 5185 & 13012 (CBS 465) & 82.0 & 31.0 & 1.30 & 5.0 \\
\hline & H. uvarum & AJ 5184 & J 13011 (CBS 2570) & 82.2 & 31.5 & 1.17 & 3.1 \\
\hline & & $\prime \prime$ & & 82.1 & 31.2 & 1.37 & 3.6 \\
\hline & $H$. valbyensis & AJ 4277 & IFO $0683(H$. melligeri $)$ & 82.1 & 31.2 & 1.35 & 4.9 \\
\hline & "I & AJ 5175 & J 13001 (IFO 0115) & 82.2 & 31.5 & 1.32 & 4.4 \\
\hline & "I & AJ 5176 & J 13003 & 82.3 & 31.7 & 1.27 & 5.5 \\
\hline & "I & AJ 5177 & J 13004 & 82.0 & 31.0 & 1.25 & 4.9 \\
\hline & K. apiculata & AJ 4798 & IFO 0175 & 82.3 & 31.7 & 1. 41 & 3.7 \\
\hline & 11 & AJ 4799 & $\mathrm{RIFY}^{f} \mathrm{HK}-3$ & 82.1 & 31.2 & 1.31 & 4.0 \\
\hline & $\prime \prime$ & AJ 4800 & banana & 82.2 & 31.5 & 1.33 & 3.2 \\
\hline & "I & AJ 5468 & CBS 104 & 82.3 & 31.7 & 1.35 & 3.3 \\
\hline \multirow{6}{*}{4} & H. valbyensis & AJ 5180 & J 13007 (IFO 0684) & 80.6 & 27.6 & 1.25 & 4.8 \\
\hline & "I & AJ 5181 & J 13008 (CBS 479) & 80.3 & 26.8 & 1.20 & 5.0 \\
\hline & & $\prime \prime$ & & 80.6 & 27.6 & 1.33 & 5.0 \\
\hline & /1 & AJ 5471 & CBS 479 & 80.4 & 27.1 & 1.34 & 5.0 \\
\hline & K. apiculata & AJ 4806 & tomato & 80.4 & 27.1 & 1.38 & 5.1 \\
\hline & /1 & AJ 4810 & tomato & 80.5 & 27.3 & 1. 40 & 5.1 \\
\hline
\end{tabular}


Table 1. (continued)

\begin{tabular}{c|c|c|l|l|l|l|l}
\hline Group & Species & Strain & Source & $\begin{array}{c}\text { Tm } \\
\left({ }^{\circ} \mathrm{C}\right)\end{array}$ & $\begin{array}{c}\mathrm{GC} \\
\text { content } \\
(\mathrm{mol} . \%)\end{array}$ & $\begin{array}{c}h \\
\max ^{a}\end{array}$ & $\begin{array}{c}\mathrm{T} \\
\left({ }^{\circ} \mathrm{C}\right)\end{array}$ \\
\hline \multirow{2}{*}{4} & K. japcnica & AJ 5206 & IFO 0151 & 80.4 & 27.1 & 1.40 & 5.3 \\
& II & AJ 5469 & CBS 281 & 80.4 & 27.1 & 1.40 & 5.4 \\
\hline
\end{tabular}

a Max. absorbance at $260 \mathrm{~m} \mu / \mathrm{min}$. absorbance at $260 \mathrm{~m} \mu$.

$b$ AJ : Central Research Laboratories, Ajinomoto Co., Inc., Kawasaki, Japan.

c J: Department of Bacteriology, School of Medicine, Juntendo University,

Tokyo, Japan.

d CBS: Centraalbureau voor Schimmelcultures, Delft, Netherlands.

$e$ IFO: Institute for Fermentation, Osaka, Japan.

$f$ RIFY: Research Institute of Fermentation, Yamanashi University, Kofu, Japan.

Kloeckera employed in the present experiment gave monophasic temperatureabsorbance curves, which indicated the uniformity of the DNA preparations. Carbon assimilation and sugar fermentation patterns of the strains employed are summarized in Table 2.

\section{Distribution of DNA base composition in the genera Hanseniaspora and Kloeckera}

The GC content of DNA from Hanseniaspora-Kloeckera distributed from 26.8 to $38.0 \%$, and the range of distribution was $11 \%$ (Table 1). The yeasts employed were classified into 4 groups by their GC contents. Each of them exhibited its specific GC values with a narrow range of variation (within $1 \%$ ), individually. Group 1 exhibited the GC content of $37.3-38.0 \%$. This group consisted of 9 strains, i.e., H. osmophila (1 strain), H. vineae (2 strains), $K$. africana (3 strains), K. corticis (2 strains), and $K$. magna (1 strain). Group 2 exhibited the GC content of $33.7-34.6 \%$, and consisted of 5 strains, namely, $K$. antillarum (1 strain), K. javanica (2 strains), $K$. jensenii (1 strain), and $K$. lafarii (1 strain). Group 3 demonstrated the GC content of 31.0-31.7\%. This group consisted of 10 strains including $H$. guilliermondii (1 strain), $H$. uvarum (1 strain), $H$. valbyensis (4 strains), and $K$. apiculata (4 strains). Group 4 exhibited the GC content of 26.8-27.6\%, and consisted of 7 strains including $H$. valbyensis (3 strains), $K$. apiculata (2 strains), and $K$. japonica (2 strains). The strains of $H$. valbyensis and its imperfect form $K$. apiculata were divided into two groups, group 3 and 4 . The type strain of the former was included in group 4 , and that of the latter in group 3.

Carbon assimilation, sugar fermentation, and vitamin requirement patterns in the genera Hanseniaspora and Kloeckera

The yeasts employed exhibited rather minor differences in carbon assimilation and sugar fermentation patterns, and no difference in vitamin re- 
Table 2. Assimilation of carbon compounds and fermentation of sugars by the members of Hanseniaspora and Kloeckera.

\begin{tabular}{|c|c|c|c|c|c|c|c|c|c|c|c|c|c|c|c|c|}
\hline \multirow[b]{2}{*}{ 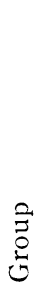 } & \multirow[b]{2}{*}{ Species } & \multirow[b]{2}{*}{ 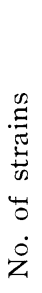 } & \multicolumn{10}{|c|}{ Assimilation $^{a}$} & \multicolumn{4}{|c|}{ Fermentation ${ }^{5}$} \\
\hline & & & مُ & 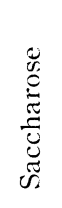 & 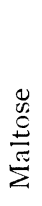 & 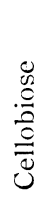 & 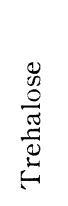 & 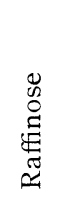 & $\begin{array}{l}\overrightarrow{0} \\
\stackrel{0}{0} \\
\stackrel{0}{0}\end{array}$ & 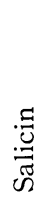 & 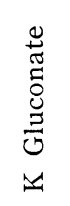 & 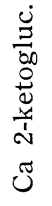 & $\begin{array}{l}0 \\
0 \\
0 \\
0 \\
己 \\
\\
\\
\dot{n} \\
\dot{n}\end{array}$ & 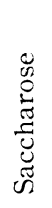 & $\begin{array}{l}0 \\
\stackrel{0}{ \pm} \\
\stackrel{\pi}{ \pm}\end{array}$ & 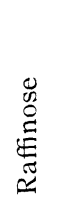 \\
\hline \multirow{5}{*}{1} & H. osmophila & 1 & + & $\mathrm{L}$ & + & + & $\mathrm{L}$ & - & - & + & - & - & + & - & + & - \\
\hline & H. vineae & 2 & + & - & + & + & $\mathrm{L}$ & - & - & + & - & - & + & - & LW & - \\
\hline & K. africana & 3 & + & $\mathrm{L}$ & + & + & $\mathrm{L}$ & - & - & W & - & - & + & $-c$ & V & - \\
\hline & K. corticis & 2 & + & $\mathrm{L}$ & + & + & & - & - & + & - & - & + & - & - & - \\
\hline & K. magna & 1 & + & $\mathrm{LW}$ & + & + & LW & - & - & + & - & - & + & - & - & - \\
\hline \multirow{4}{*}{2} & K. antillarum & 1 & + & + & - & + & $\mathrm{LW}$ & LW & + & + & - & - & + & + & - & $\mathrm{L}$ \\
\hline & K. javanica & 2 & + & + & - & + & $\mathrm{L}$ & LW & + & + & - & - & + & + & - & LW \\
\hline & K. jensenii & 1 & + & + & - & + & LW & - & + & + & - & - & + & + & - & - \\
\hline & K. la farii & 1 & + & + & - & + & $\mathrm{LW}$ & LW & + & + & - & - & + & + & - & - \\
\hline \multirow{4}{*}{3} & H. guilliermondii & 1 & + & - & - & + & $\mathrm{L}$ & - & - & + & $\mathrm{L}$ & + & + & - & - & - \\
\hline & H. uvarum & 1 & + & - & - & + & $\mathrm{L}$ & - & - & + & + & + & + & - & - & - \\
\hline & H. valbyensis & 4 & + & - & - & + & $\mathrm{L}$ & - & - & + & + & + & + & - & - & - \\
\hline & K. apiculata & 4 & + & - & - & + & $\mathrm{L}$ & - & - & + & + & + & + & - & - & - \\
\hline \multirow{3}{*}{4} & H. valbyensis & 3 & + & - & - & + & $\mathrm{L}$ & - & - & + & $\mathrm{L}$ & - & + & - & - & - \\
\hline & K. apiculata & 2 & + & - & - & + & $\mathrm{L}$ & - & - & + & $\mathrm{LW}$ & - & + & - & - & - \\
\hline & K. japonica & 2 & + & - & - & + & + & - & - & + & + & - & + & - & - & - \\
\hline
\end{tabular}

L: Latent, W: Weak, LW: Latent and weak, V: Variable

a D-Galactose, lactose, L-sorbose, melibiose, melezitose, inulin, soluble starch, D-xylose, L-arabinose, D-arabinose, D-ribose, L-rhamnose, ethanol, erythritol, adonitol, dulcitol, D-mannitol, D-sorbitol, $\alpha$-methyl-D-glucoside, DL-lactic acid, succinic acid, citric acid, and inositol were not utilized by any of the strains tested.

$b$ D-Galactose and lactose were not fermented by any of the strains tested.

c One strain (AJ 5173) fermented saccharose very weakly.

quirement. All the strains assimilated D-glucose, cellobiose, trehalose, and salicin, fermented D-glucose, and required biotin, calcium-pantothenate, inositol, niacin, pyridoxine, and thiamine. Differences were found in assimilation of saccharose, maltose, raffinose, glycerol, potassium-gluconate, and calcium-2ketogluconate, and in fermentation of saccharose, maltose, and raffinose, by which 4 groups were discriminated. This grouping agreed with that based on the GC content. Strains belonging to group 1 assimilated D-glucose, 
maltose, cellobiose, trehalose, and salicin though assimilation of trehalose and salicin was often latent or weak. Saccharose was latently assimilated or not assimilated by this group of yeasts. In addition to D-glucose, strains of this group often fermented maltose and saccharose though fermentation of maltose is variable and that of saccharose was very weakly demonstrated by only one strain (K. africana AJ 5173). In group 2, good assimilation of Dglucose, saccharose, cellobiose, glycerol, and salicin, latent or latent and weak assimilation of trehalose were observed. Raffinose was assimilated latently and weakly, or not assimilated. D-Glucose and saccharose were rapidly fermented but the fermentation of raffinose was latent, latent and weak, or not demonstrated by this group of yeasts. Group 3 assimilated D-glucose, cellobiose, trehalose (latent), salicin, potassium-gluconate and calcium-2-ketogluconate, and fermented only D-glucose. Yeasts belonged to group 4 assimilated D-glucose, cellobiose, trehalose (often latent), salicin, and potassiumgluconate (often latent, or latent and weak), and fermented only D-glucose.

\section{DISCUSSION}

According to Miller and PhafF (6), the species of the genus Hanseniaspora and its imperfect counterpart Kloeckera make a natural group. However, GC contents of DNAs from Hanseniaspora and Kloeckera distributed widely from 26.8 to $38.0 \%$. The members of Hanseniaspora and Kloeckera employed were classified into 4 groups on the basis of the GC content and this classification agreed with that based on biochemical criteria commonly used in yeast taxonomy. The characterization of these groups is summarized in Table 3. The respective group exhibited its specific GC content with deviation below $1 \%$. This deviation is considered to be due to technical error. Consequently, each group consists of strains whose GC contents are actually the same, and whose carbon assimilation and sugar fermentation patterns are nearly the same. These facts suggest that each group of this pair of yeast genera consists of a single species, or at least some of closely related species. The yeasts employed exhibited rather minor difference in taxonomic criteria commonly employed in spite of the difference in GC content. However, they were clearly differentiated from one another by assimilation of maltose, glycerol, and calcium-2-ketogluconate as shown in Table 2. It is considered that a small difference found in carbon assimilation pattern should not be neglected in yeast taxonomy, especially in yeasts where only a restricted number of carbon compounds can be utilized.

Group 1 which demonstrated the highest values of the GC content (37.3-$38.0 \%$ ) in the genera Hanseniaspora and Kloeckera consisted of two perfect species ( $H$. osmophila and $H$. vineae) and three imperfect ones (K. africana, $K$. corticis, and $K$. magna). MILlER and PHAFF (6) reported that $K$. africana was different from the group of $K$. corticis because the former could assimilate saccharose. On the other hand, TsuchiY A et al. (8) included this species 
Table 3. Characterization of groups in the genera Hanseniaspora and Kloeckera.

\begin{tabular}{|c|c|c|c|c|c|c|}
\hline \multirow[b]{3}{*}{ 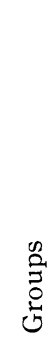 } & \multirow{2}{*}{\multicolumn{2}{|c|}{ Species }} & \multirow{3}{*}{$\begin{array}{c}\text { GC } \\
\text { content } \\
(\text { mol. \%) }\end{array}$} & \multicolumn{2}{|c|}{ Assimilation } & \multirow{3}{*}{$\begin{array}{c}\text { Antigenic } \\
\text { structure } \\
\text { by TsuchIYA } \\
\text { et al. }(8)\end{array}$} \\
\hline & & & & & \& & \\
\hline & $\begin{array}{c}\text { Perfect form } \\
\text { (Hanseniaspora) }\end{array}$ & $\begin{array}{l}\text { Imperfect form } \\
\text { (Kloeckera })\end{array}$ & & 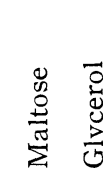 & 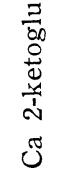 & \\
\hline 1 & $\begin{array}{l}\text { H. osmophila } \\
\text { H. vineae? }\end{array}$ & K. africana & $37.3-38.0$ & +- & - & $\begin{array}{l}1,2,3,5,6 \\
7,40\end{array}$ \\
\hline 2 & ? & K. Javanica & $33.7-34.6$ & -+ & - & $\begin{array}{l}1,2,3,5,6, \\
7,8,10,28,40\end{array}$ \\
\hline 3 & $\begin{array}{l}\text { H. guilliermondii } \\
\text { H. uvarum }\end{array}$ & K. apiculata & $31.0-31.7$ & - & + & $1,8,10,28, l$ \\
\hline 4 & H. valbyensis & K. japonica? & $26.8-27.6$ & -- & - & $\begin{array}{l}1,8,10,28, l \\
\text { or } \\
1,8,10,28\end{array}$ \\
\hline
\end{tabular}

in the group of $K$. corticis on the basis of antigenic structure. Since the assimilation of saccharose was found to be variable in various strains of this group in the present experiment (Table 2), it is not reasonable to separate $K$. africana from $K$. corticis by reason of assimilation of saccharose. $K$. africana AJ 5172 was received from Prof. TsUCHIYA under the name of $K$. antillarum, and reidentified with this species by the present authors. This strain demonstrated the same carbon assimilation and sugar fermentation patterns as $K$. africana, and differed from the descriptions of $K$. antillarum by Lodder and Kreger-van Rij (2), and by Miller and Phaff (6), though it was derived from the type strain of $K$. antillarum. Since TsuchiYA et al. (8) reported that $K$. antillarum exhibited the same antigenic structure with $K$. africana group, a mislabeling might have occurred before their antigenic analysis had been made. Two perfect species, $H$. osmophila and $H$. vineae, were included in this group as mentioned above. Miller and PhAFF (6) considered that $H$. vineae was a synonym of $H$. osmophila, while NovíK and ZSOLT (7) placed the former in their new genus Vanderwaltia because $H$. vineae formed ascospores with warty sporewall. TsuchIY A et al. (8) reported that the antigenic structure of $H$. vineae was the same as $H$. osmophila$K$. africana. The present authors consider that two yeasts which exhibit actually the same GC contents, the same antigenic structures, and the same carbon assimilation and sugar fermentation patterns should not be placed in different genera in which relation of perfect and imperfect does not exist, 
though they do not intend to ignore the significance of the morphology of ascospores in yeast taxonomy. It is apparent that these two yeasts represent the same, or at least closely related, species though further study may be necessary to evaluate the validity of $H$. vineae. The proper name of imperfect species of this group is $K$. africana, and $K$. corticis and K. magna can be regarded as synonyms of $K$. africana. This group is easily discriminated from the other 3 groups by assimilation of maltose (Table 3 ).

Group 2 which demonstrated the GC content of $33.7-34.6 \%$ consisted of $K$. antillarum, $K$. javanica, $K$. jensenii, and $K$. lafarii. TsuchiYA et al. (8) deduced from the antigenic structure that $K$. javanica group was a hybrid of $K$. africana group and $K$. apiculata group. This assumption was supported by SPENCER and GoRIN (9) on the basis of proton magnetic resonance spectra of mannans isolated from these yeasts. It is interesting that the GC content of the species of group 2 was in an intermediate position between those of groups 1 and 3 (Table 1), though it seems unlikely that two microorganisms whose GC content differed about $7 \%$ from each other are able to hybridize. Miller and PhAFF (6) separated $K$. lafarii as $K$. javanica var. lafarii from $K$. javanica by the lack of assimilation and fermentation of raffinose. In the present experiment, however, K. lafarii apparently assimilated raffinose but latently and weakly. Since, as MilleR and PHAFF (6) reported, assimilation and fermentation of this sugar by the group of $K$. javanica were always latent, or latent and weak (Table 2), these properties have indicated a minor taxonomic value in the classification of Hanseniaspora and Kloeckera so that there is no need to maintain $K$. javanica var. lafarii. From this consideration, the proper name of this group is $K$. javanica. $K$. antillarum, $K$. jensenii, $K$. lafarii, and $K$. javanica var. lafarii can be regarded as synonyms of $K$. javanica. This group is easily discriminated from the other ones by assimilation of glycerol (Table 3 ).

Group 3 which exhibited the GC content of $31.0-31.7 \%$ consisted of $H$. guilliermondii, $H$. uvarum, 4 out of 7 strains of $H$. valbyensis, and 4 out of 6 of $K$. apiculata. The type strain of $H$. valbyensis was not included in this group but in the following group 4. LODDER and KREGER-VAN RIJ (2) considered that $H$. guilliermondii and $H$. melligeri were synonyms of $H$. valbyensis, while KREGER-VAN RIJ and AHEARN (15) suggested a separation of $H$. guilliermondii (including $H$. melligeri) from $H$. valbyensis on the basis of the number of ascospores per ascus and growth at $37^{\circ}$. The GC content ciearly indicated that their suggestion was reasonable. Namely, H. guilliermondii (including $H$. melligeri) exhibited the GC content about $4 \%$ higher than that of $H$. valbyensis (Table 1). Four cultures labeled $H$. valbyensis in group 3 should be identified with $H$. guilliermondii. Thus, two perfect species, $H$. guilliermondii and $H$. uvarum, are retained in this group though the difference between these two species was much reduced by the finding of "ledge" on the spore of H. uvarum (15). Since the type strain of $K$. apiculata (CBS 104) was included in this group, $K$. apiculata is not the imperfect form of 
$H$. valbyensis as formerly believed $(2,6)$ but that of $H$. guilliermondii and $H$. uvarum. This group is easily discriminated from the other ones by assimilation of calcium-2-ketogluconate.

Group 4 which demonstrated the GC content of $26.8-27.6 \%$ consisted of 3 strains of $H$. valbyensis including its type strain (CBS 479), 2 strains of $K$. apiculata, and $K$. japonica. In taxonomic criteria commonly employed, this group resembles group 3, and assimilation of calcium-2-ketogluconate is the only character to differentiate these two groups from each other. However, about $4 \%$ of difference in the GC content indicates that these two groups represent distinct species, or group of species. According to TSUCHIYA (personal communication), H. valbyensis J 13007 (AJ 5180) and J 13008 (AJ 5181) exhibited the same antigenic structures with H. valbyensis J 13001 (AJ 5175 ) which was included in group 3 in the present experiment. It was already reported in the case of Hansenula (16) that yeasts exhibiting the same antigenic structure did not necessarily exhibit the same GC content. In the monograph of LODDER and KREGER-VAN RIJ (2), K. japonica described by SAITO and OHTANI (17) was treated as a synonym of $K$. apiculata with a question mark. On the other hand, NOVÁK and ZSOLT ( 7$)$ considered this species as a synonym of $K$. jensenii. It is apparent that $K$. japonica is neither $K$. apiculata nor $K$. jensenii because these two species belong to groups 3 and 2, respectively. The present authors listed $K$. japonica as the imperfect species of this group with a question mark in Table 3 because they did not study all the synonyms of $K$. apiculata listed in the monograph of LODDER and KREGER-VAN RIJ (2).

The authors wish to thank Prof. T. Tsuchiya and Dr. Y. Fukazawa for their invaluable comments on the present work and their kindness in supplying them the authentic cultures. Many thanks are also due to Dr. T. Hasegawa for his kind supply of authentic cultures, and to Miss S. Miyazawa for her technical assistance.

\section{REFERENCES}

1) M. REEss, Botanische Untersuchungen über die Alkoholgärungspilze, Leipzig (1870: cited from references 2 .

2) J. Lodder and N.J.W. Kreger-van RiJ, The Yeasts, a Taxonomic Study, NorthHolland Publ. Co., Amsterdam (1952).

3) A.M. El Tabey Shehata, E.M. Mrak and H.J. Phaff, Mycologia, 47, 799 (1955).

4) J.P. VAN Der WAlt and I.T. Tscheuschner, Trans. Brit. Mycol. Soc., 40, 211 (1957).

5) N. VAn Uden and L. Assis-Lopez, Arch. Mikrobiol., 19, 262 (1953).

6) M.W. Miller and H.J. Phaff, Mycopathol. Mycol. Appl., 10, 113 (1958).

7) E.K. Novák and J. Zsolt, Acta Bot. Hung., 7, 93 (1961).

8) T. Tsuchiya, S. Kawakita, M. Imai and K. Miyagawa, Japan. J. Expil. Med., 36, 555 (1966)

9) J.F.T. Spencer and P.A.J. Gorin, J. Bacteriol., 96, 180 (1968).

10) L.J. Wickerham, Taxonomy of Yeasts, U.S.D.A. Tech. Bull., No. 1029 (1951). 
11) K. Komagata and T. NAKASE, Shokuhin Eiseigaku Zasshi, 8, 53 (1967).

12) T. Nakase and K. Komagata, J. Gen. Appl. Microbiol., 14, 345 (1968).

13) J. MARMUR and P. Doty, J. Mol. Biol., 5, 109 (1962).

14) K. Yamada and K. Komagata, J. Gen. Appl. Microbiol., 16, 215 (1970).

15) N.J.W. KREger-VAN Rij and D.G. AheArn, Mycologia, 60, 604 (1968).

16) T. Nakase and K. Komagata, J. Gen. Appl. Microbiol., 15, 85 (1969).

17) K. SAito and Y. OhtANI, Jozogaku Zasshi, 9, 9 (1931). 